\title{
SOME OBSERVATIONS ON THE NESTING BEHAVIOUR AND FOOD OF THE SPOTTED OWLET ATHENE BRAMA
}

\author{
Anika Jadhav and B.M. Parasharya \\ AINP on Agricultural Ornithology, Gujarat Agricultural University, Anand, Gujarat 388110, India. \\ E-mail:anika@gau.guj.nic.in,parasharya@satyam.com
}

\begin{abstract}
Observations on the nesting behaviour and food of the Spotted Owlet Athene brama occupying a wooden nest box were recorded in March-April 2002 at Anand, Gujarat. The clutch size was three and average egg measurements were: length $30.9 \mathrm{~mm}$, width $26.3 \mathrm{~mm}$, weight $11.6 \mathrm{~g}$. An egg was destroyed due to a crack in the shell during later stage of the incubation. A young chick died, probably due to a dipteran parasite. Removal of old nest material helped to get rid of the parasite and survival of the other chick. Regurgitated pellets of the adults contained coleopteran beetles and other insects and mammalian fur. Marbled Toad Bufo stomaticus and cockroach Periplanata americana were dominant food items in the diet of the young one. Toads were recorded for the first time in the diet of the Owlet. Blind snake and bat were also recorded.
\end{abstract}

\section{Keywords}

Athene brama, food, nesting behaviour, Spotted Owlet

\section{Introduction}

The Spotted Owlet Athene brama is a resident bird found throughout India (Ali \& Ripley, 1983) including Gujarat (Ali, 1954). Except for an ecological study carried out at Hyderabad (Kumar, 1985), very little is known about the breeding (Ali \& Ripley, 1983) and food habits (Ali \& Ripley, 1983; Jain \& Advani, 1983) of this most common resident Owlet. Hence a study was conducted on the nesting behavior and food of the owlet occupying a nest box hung on the wall of our laboratory. The wooden box has been hanging on the wall of the first floor of Biocontrol Laboratory, Gujarat Agricultural University, Anand $\left(22^{\circ} 32^{\prime} \mathrm{N}, 73^{\circ} 00^{\prime} \mathrm{E}\right)$, Gujarat, since the last five years. Indian Myna (Acridotheres tristis) and Spotted Owlet (Athene brama) use this nest box for nesting during different seasons, viz. Spotted Owlet during February to April-May and Indian Myna during May to September.

\section{Observations}

On 27 March 2002, a pair of Spotted Owlets was observed occupying the nest box. When we checked the box, there were three eggs inside. The same box was occupied by an Indian Myna previously so there was old nesting material on which the Spotted Owlet had laid its eggs.

Nest box dimensions: Length/height - $20.5 \mathrm{~cm}$; width - $14.3 \mathrm{~cm}$; depth $-11.0 \mathrm{~cm}$; diameter of entrance hole $-6.0 \mathrm{~cm}$.

Eggs: Colour white, without any markings. Eggs were measured using a digital Vernier calipers $(0.01 \mathrm{~mm}$ sensitivity). Weight was taken on a Pesola spring balance (0.2g sensitivity).

The nest box was observed on every alternate day at around 0900 and $1600 \mathrm{hr}$. An adult owlet of unknown sex was observed incubating the eggs. The bird was conscious about the surrounding environment. On some disturbance, it flew away from the nest giving an alert call and perched on a Peltophorum pterocarpum tree near the building. Sometimes two owlets were observed sitting on the Peltophorum tree.

On April 16, 2002 there were two chicks in the nest box while the third egg had not hatched. A slight crack was noticed in the shell of the third egg. We opened the egg on 22 April and found that it was a fertilized egg with fully developed embryo indicating that the damage had occurred during later stage of incubation. The two young ones were covered with white downy feathers. Their eyes were closed. On 18 April 2002, we found only one chick inside the box and the other was missing. The chick was taken out of box and observed. Many maggots were found, stuck to its body. These maggots were carefully removed from the body with the help of forceps. We completely removed the old decaying nest material and cleaned the box before placing the young one back. After that we never found any maggot on 
Table 1. Physical measurement of the eggs

\begin{tabular}{lllll}
\hline Sr. No. & Length $(\mathrm{mm})$ & Breath $(\mathrm{mm})$ & Weight $(\mathrm{g})$ & ESI \\
\hline 1 & 30.1 & 26.0 & 11.0 & 86.37 \\
2 & 31.4 & 26.3 & 12.0 & 83.75 \\
3 & 31.2 & 26.8 & 12.0 & 85.89 \\
Average & 30.9 & 26.4 & 11.67 & 85.34 \\
\hline
\end{tabular}

Egg Shape Index (ESI) (Romanoff and Romanoff, 1963) = b/l * 100

where, $b=$ maximum breath $(\mathrm{mm}), \mathrm{I}=$ length $(\mathrm{mm})$

the chick's body. The fully grown chick came out of the nest on 13 May 2002 and sat on a branch of a Peltophorum pterocarpum tree. The parent bird was also observed perched on the nearby branch of the same tree. We observed both the birds till evening. Next day, neither the adult nor the chick was seen in or around the nest. The nestling period of a single chick brood was 28-30 days.

\section{Discussion}

Spotted Owlet is known to nest in natural hollows of tree-trunks, holes in dilapidated walls or between the ceiling and roof of deserted as well as occupied dwellings. Its nest is sometimes, lined with a little grass, tow, and feathers (Ali \& Ripley, 1983). However, in our study, the Spotted Owlet was recorded to nest in the artificial wooden nest-box since last five years. The nestbox with the given dimensions seems to be comfortable for the bird to nest. Thus wooden nest-boxes could play an important role in providing appropriate nesting sites.

The average size of the eggs was slightly less (i.e. $30.9 \times 26.3 \mathrm{~mm}$ ) than the one given by Baker, i.e., 32.2 x 27.1mm (Ali \& Ripley, 1983) and recorded at Hyderabad (Kumar, 1985). Earlier, weight of the owlet's egg was recorded only from Hyderabad (Kumar, 1985). Present study showed that egg weight at Anand was significantly lower $(>1.6 \mathrm{~g})$ than the one at Hyderabad. The ESI value was nearer to one, suggesting the roundish shape of the egg. The nestling period recorded here was close to the one recorded at Hyderabad, i.e. 29-34 days.

Nothing is known about the reason behind the disappearance of the first chick. A possibility of predation is less, as we never saw any predator approaching the box during daytime. The box is inaccessible to snakes as it is fixed up very high on a building wall. Since one chick had remained alive and only one was lost, we reject the possibility of predation. Hence we presume that maggots had killed the first chick. The parents might have removed the dead chick from the nest. Dipteran maggots are known to cause heavy chick mortality in cavity nesting birds like House Sparrow Passer domesticus, Brahminy Myna Sturnus pagodarum (Patel, 1991), Bank Myna Acridotheres ginginianus (Parasara, 1989) and Indian Myna Acridotheres tristis (Chauhan, 1994). Decaying nest material in a nest box might attract dipteran flies from long distances. It seems advisable that a nest box be cleaned after the occupant species completes its nesting. This will certainly reduce the risk of parasitisation by maggots.

\section{Food}

Spotted Owlet is a nocturnal predatory bird and is known to feed chiefly on beetles, moths, locusts and other insects, also earthworms, lizards, mice and small birds (Ali \& Ripley, 1983). A preliminary study of food of the owlet was also done while observing the breeding behaviour of the bird. The observations were recorded since the chick hatched from the egg and left the nest.

\section{Methods}

The diet composition of the Spotted Owlet was studied by the analysis of the materials found in the pellets and the prey remains collected from the nest box and its vicinity.

Adult bird was noted to regurgitate the undigested parts of food in the form of pellets. As the adult bird used to perch on the nearest Peltophorum tree, we could collect the pellets that were dropped below the perching place. Such pellets were collected, bagged and kept in an oven at $70^{\circ} \mathrm{C}$ for $24 \mathrm{hr}$ in order to kill infesting insects and stored. Later, the pellets were kept in $8 \% \mathrm{NaOH}$ for two minutes, the osteous and chitinous remains were separated and then washed for further identification (Neelanarayanan et al., 1998).

After eating the prey, the hard body parts (bones etc.) were left behind, and were either thrown out of the nest box or kept aside in the box. These unconsumed body fragments of the prey were gathered from the nest box as well as from the vicinity of the nest. The collected material was then examined and sorted.

\section{Results}

The regurgitated pellet consisted of smooth fur and hair, small pieces of vertebrate bones, pieces of insect integuments, insect appendages etc. However, this material was so crushed that it was very difficult to identify the taxa to which they belonged. However, appendages of coleopteran beetles were predominant in the pellets.

In the prey remains collected from the nest box and its vicinity, we could collect some body parts of insects and vertebrates. Some insects were identified by their wings and others by their body parts i.e. head region, limbs, etc. that were left behind in the box after eating the rest of the body. 
The taxa comprising the food of Spotted Owlet were as follows. Insecta: Order - Coleoptera: Family - Scarabaeidae: Dung Roller Beetle - Helicopris bucephalus; Family - Elateridae: Click Beetle - Drasterius sp.; Family - Melolonthidae: White Grub Beetle Holotrichea sp.; Order - Odonata: Dragonfly (Agrionine sp.); Order - Lepidoptera: Family - Sphingidae: Moth; Order Dictyoptera: Cockroach (Periplanata americana).

Amphibia: Marbled Toad (Bufo stomaticus)

Reptilia: Brahminy Worm Snake (Ramphotyphlops braminus). Mammalia: House Mouse (Mus musculus), Bats (Microchiropteran).

\section{Discussion}

We could collect more number of body parts of cockroach and Bufo stomaticus among the invertebrates and vertebrates respectively. During the entire study we found one specimen each of mouse, Brahminy Worm Snake and bat while we collected about 29 different body parts of Bufo stomaticus, out of these 10 specimens consisted of two hind limbs attached to the back region. This indicates that the chick consumed a minimum of 10 individuals of toad. Ali and Ripley (1983) had not recorded any amphibian in the diet of the owlet. Kumar (1985) had recorded only frogs in the diet of the Spotted Owlet at Hyderabad. Hence, toad is being reported for the first time in the diet of the owlet. It is said that the presence of poison glands on the toad's skin helps to avoid predators (Daniel, 2002). However, it seems that the same is not effective against Spotted Owlet.

The snake, Ramphotyphlops braminus was actually collected below the nest box and its body was intact. Presumably the snake might have escaped while it was being fed to the young one. Kumar (1985) had recorded Ramphotyphlops braminus in the gut of Spotted Owlet. Live or dead blind snakes within the nest boxes of Indian Myna or in the diet of Indian Myna have been reported from this campus (Chauhan, 1994). However, the presence of small-sized snakes in the nest of some owl species is said to biologically control the arthropod larvae parasitic on the chicks (Gelbach \& Baldridge, 1987).

The most surprising item in the diet of the Spotted Owlet was of the bat. We could collect one specimen of bat from the nest. It comprised of two forelimbs along with the petagium and all digits and one hind limb. The bat was identified as a Microchiropteran by the characters of it forelimb (Bates \& Harrison, 1997). The head and trunk were missing. Kumar did not find bats in the gut content of Spotted Owlet, however, he found remains of bats from only two nest boxes; he opined that bats may not be a regular food item in the diet of the owlets. Hence it remains to be verified if bats form a regular item in the diet of the owlet as relative abundance of bats may vary in different environment.

\section{Acknowledgements}

We thank Dr. Raju Vyas (Sayajibaug Zoo, Vadodara) who helped us identify the amphibian species. We are also grateful to Dr. D.N. Yadav (Biocontrol Lab. G.A.U., Anand) for identifying the insects comprising the food of the owlet.

\section{References}

Ali, S. (1954). The birds of Gujarat. Journal of the Bombay Natural History Society 52: 374-458.

Ali, S. and S.D. Ripley (1983). Handbook of the Birds of India and Pakistan. Compact Edition. Oxford University Press, Delhi. xxxiii+737pp.

Bates, P.J.J. and D.L. Harrison (1997). Bats of the Indian Subcontinent. Harrison Zoological Museum, Kent, xvi+257pp.

Chauhan, R.B. (1994). Food habit, breeding performance and morphometrics of the Indian Myna Acridotheres tristis L. M.Sc. Thesis. Gujarat Agricultural University, Anand.

Daniel, J.C. (2002). The Book of Indian Reptiles and Amphibians. Bombay Natural History Society - Oxford University Press, Mumbai. viii+238pp.

Gelbach, F.R. and R.S. Baldridge (1987). Live blind snakes (Leptotyphlops dulcis) in Eastern Screech Owl (Otus asio) nests: a novel commensalism. Oecologia 71: 560-563.

Jain, A.P. and R. Advani (1983). Winter food of Spotted Owlet. Journal of Bombay Natural History Society 80(2): 415-416.

Kumar, T.S. (1985). The life history of the Spotted Owlet (Athene brama Temminck) in Andhra Pradesh. Raptor Research Centre, Hyderabad, 241pp.

Neelanarayanan, P., R. Nagarajan and R. Kanakasabai (1998). Studying diet of Barn Owl Tyto alba Stertens by pellet analysis. pp.125-131. In: Dhindsa, M.S., P.S. Rao and B.M. Parasharya (Editors). Birds in Agricultural Ecosystem. Society for Applied Ornithology, India, 196pp.

Parasara, U.A. (1989). Role of Avian predators in Heliothis armigera Hübner management and breeding biology of the Bank Myna Acridotheres ginginianus L. M.Sc. Thesis Gujarat Agricultural University, Anand.

Patel, J.R. (1991). Role of avian predators, other bioagents and cutting management in control of Lucerne (Medicago sativa L.) pests and breeding biology of Brahminy Myna Sturnus pagodarum G. M.Sc. Thesis. Gujarat Agricultural University, Anand.

Romanoff, L. and J. Romanoff (1963). The Avian Egg. John Wiley and Sons Inc., New York. 